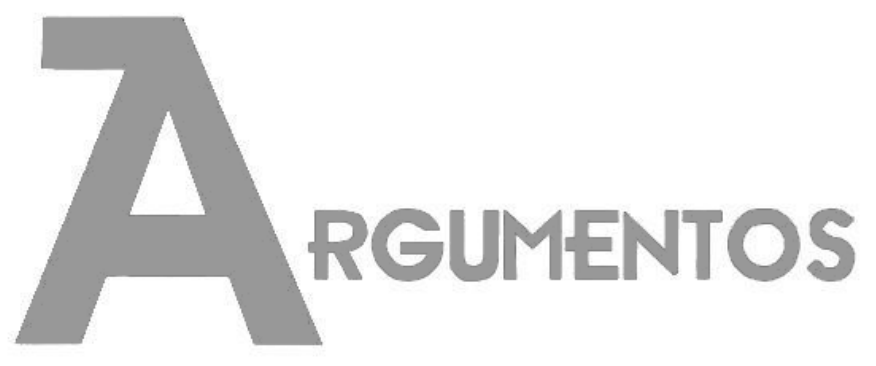

Vol. 18, n. 1, jan./jun. 2021 ISSN: 2527-2551 (online)

\title{
Relação entre representação descritiva e substantiva: o caso da Assembleia Legislativa de Minas Gerais (ALMG)
}

Anne Karoline Rodrigues Vieira ${ }^{1}$

Recebido em: 02/12/2019

Aprovado em: 20/08/2020

\begin{abstract}
Resumo: Este artigo tem como objetivo principal detectar a existência ou não da relação entre representação descritiva e representação substantiva, ao se analisar a atuação para minorias sociais. Para isso, primeiramente se realizou uma revisão de literatura sobre representação descritiva, tendo como base autoras como Pitkin, Phillips e Young, perpassando conceitos como perspectiva e política de presença, para compreender como a necessidade da representação dos grupos subalternos, nos espaços de decisão política, foi debatido. Posteriormente, é apresentado como a relação entre representação descritiva e representação substantiva podem não estar diretamente vinculados como se poderia supor. Buscando alcançar o objetivo proposto, foi realizada a coleta de dados referentes aos projetos apresentados pelos deputados mineiros nas 11a (1987-1991) e 17a (2011-2015) legislaturas da Assembleia Legislativa de Minas Gerais. Com a apresentação dos dados percebeu-se que as políticas para esses grupos são poucas e que os deputados selecionados - considerados como representantes descritivos das minorias - não apresentam uma atuação tão focada nesses grupos, principalmente quando comparada com a atuação do universo de deputados nas duas legislaturas. Além disso, existem minorias que não são representadas por esses deputados, como as comunidades tradicionais e o grupo LGBT, enquanto grupos considerados menos progressistas tem sua representação garantida.
\end{abstract}

Palavras-chave: ALMG; grupos minoritários; representação descritiva; representação substantiva; responsividade.

\section{Relación entre representación descriptiva y sustantiva: el caso de la Asamblea Legislativa de Minas Gerais (ALMG)}

Resumen: Este artículo tiene como principal objetivo detectar la existencia o no de la relación entre representación descriptiva y representación sustantiva al analizar el desempeño de las minorías sociales. Para eso, en primer lugar, se realizó una revisión de la literatura sobre

\footnotetext{
${ }^{1}$ Doutoranda em Ciência Política (UnB), Brasil; Pesquisadora do grupo de pesquisa Resocie - Repensando as relações entre sociedade e Estado. E-mail: annervieira@gmail.com. ORCID: https://orcid.org/00000002-3609-7786.
} 
representación descriptiva, basada en autoras como Pitkin, Phillips y Young, analizando conceptos como la perspectiva y la política de presencia, para comprender cómo se debatió la necesidad de la representación de grupos subordinados en espacios de decisión política. Posteriormente, se presenta cómo la relación entre la representación descriptiva y la representación sustantiva puede no estar directamente vinculada como se esperaba. Buscando lograr el objetivo propuesto, se recopilaron datos sobre los proyectos presentados por los diputados de Minas Gerais en las legislaturas 11.a (1987-1991) y 17.a (2011-2015) de la Asamblea Legislativa de Minas Gerais. Con la presentación de los datos se notó que las políticas para estos grupos son pocas y que los diputados seleccionados - considerados como representantes descriptivos de minorías - no tienen un desempeño tan enfocado en estos grupos, especialmente cuando se compara con el desempeño del universo de diputados en las dos legislaturas. Además, hay minorías que no están representadas por estos parlamentarios, como las comunidades tradicionales y el grupo LGBT, mientras que los grupos considerados menos progresistas tienen su representación garantizada.

Palabras-clave: ALMG; grupos minoritarios; representación descriptiva; representación sustantiva; capacidad de respuesta.

\section{Relationship between descriptive and substantive representation: the case of the Legislative Assembly of Minas Gerais (ALMG)}

Abstract: This article has as main objective to detect the existence or not of the relationship between descriptive representation and substantive representation when analyzing the performance for social minorities. For this, first, a literature review on descriptive representation was conducted, based on authors such as Pitkin, Phillips and Young, going through concepts such as perspective and presence politics, to understand how the need for the representation of subordinate groups in political decision spaces was debated. Subsequently, it is presented how the relationship between descriptive representation and substantive representation may not be linked as expected. Seeking to achieve the proposed objective, data were collected regarding the projects presented by the deputies of Minas Gerais in the 11th (1987-1991) and 17th (2011-2015) legislatures of the Legislative Assembly of Minas Gerais. With the presentation of the data it was noticed that the policies for these groups are few and that the selected deputies - considered as descriptive representatives of minorities - do not have such a focused performance in these groups, especially when compared with the performance of the universe of deputies in the two legislatures. In addition, there are minorities that are not represented by these MPs, such as the traditional communities and the LGBT group, while groups considered less progressive have their representation guaranteed.

Keywords: ALMG; minority groups; descriptive representation; substantive representation; responsiveness.

\section{Introdução}

As premissas liberais de igualdade e liberdade formal por meio da expressão individual no voto são desafiadas por autoras (Young, 2006; Phillips, 2001, 2009) que advogam a favor da representação descritiva, em busca do rompimento com a premissa liberal de que o indivíduo é o único sujeito político legítimo, revelando as desigualdades sociais que excluem diversos grupos da política. Com isso, defende-se a presença dos 
Artigos | Relação entre representação descritiva e substantiva: o caso da Assembleia Legislativa de Minas Gerais (ALMG) (VIEIRA, Anne Karoline Rodrigues)

grupos excluídos nos espaços de decisão, para que as suas perspectivas sejam incluídas na agenda política (Almeida, 2015)².

Essa inclusão dos grupos subalternos é defendida, pois se acredita que a presença deles, nos espaços de tomada de decisão, possa permitir a inclusão de temas diferenciados na agenda política e maior responsividade em relação aos mesmos. Assim, aumenta-se a demanda por representação de grupos e da igualdade, considerada a partir das características e identidade dos cidadãos, ao contrário da igualdade universal da representação liberal (Young, 2006). Com isso, os grupos excluídos da arena política seriam beneficiados com a aprovação de projetos que contemplariam diretamente as suas vidas, uma vez que interesses surgem de experiências de grupos (Pinheiro, 2007). Como afirma Mansbridge (1999, p. 644),

Quando os interesses não são cristalizados, a melhor maneira de ter os mais importantes interesses substantivos representados é, muitas vezes, escolher um representante cujas características descritivas correspondam às questões que se espera que surjam ${ }^{3}$.

A esperança, segundo Williams (1998), é que a presença dos representantes dos grupos marginalizados produzirá mudanças na dinâmica legislativa. Entretanto, como é colocado pela própria autora, apenas a presença dos representantes desses grupos no legislativo pode não garantir que eles serão capazes de promover mudanças políticas que são de interesse dos seus constituintes, ou que esses interesses serão bem representados e defendidos.

Levando essas questões em consideração, este artigo é dedicado à análise e discussão da relação entre representação descritiva e a atuação para grupos marginalizados socialmente. Para isso, são apresentados dados empíricos acerca de projetos de lei, analisando-os à luz desses conceitos, com o propósito de avaliar a atuação parlamentar. Para a pesquisa foram selecionadas duas legislaturas da Assembleia Legislativa de Minas Gerais - ALMG, a 11a e a 17ạ. A escolha dessas legislaturas se justifica porque a 11 1 a foi a primeira composta após a ditadura militar,

\footnotetext{
${ }^{2}$ Este artigo é resultante da dissertação de mestrado produzida pela autora.

${ }^{3}$ Tradução livre do inglês: "When interests are uncrystallized, the best way to have one's most important substantive interests represented is often to choose a representative whose descriptive characteristics match one's own on the issues one expects to emerge" (Mansbridge, 1999, p. 644).
} 
Artigos | Relação entre representação descritiva e substantiva: o caso da Assembleia Legislativa de Minas Gerais (ALMG) (VIEIRA, Anne Karoline Rodrigues)

sendo importante ver como os parlamentares atuaram em um momento em que a abertura democrática coincidia com uma atuação voltada para o social, considerando mais as minorias. Nesse período foi percebido um novo padrão de interação entre sociedade e parlamentares - com a realização de Simpósios para criação de políticas base para inovações institucionais que surgiriam a partir daí. A 17ạ legislatura se justifica pelo fato desse ser um período em que ainda se reflete a ampliação de políticas voltadas para direitos das minorias no Brasil nos últimos anos, principalmente após a eleição do presidente Lula, com implantação de diversas Secretarias, como a Secretaria de Políticas de Promoção da Igualdade Racial, e o aumento na realização de conferências em áreas de direitos de minorias. Isso acaba se reproduzindo no nível estadual, com a realização de conferências para debater questões de mulheres, idosos e pessoas em situação de vulnerabilidade socioeconômica, apesar de Minas Gerais ser governada, naquele período, pelo Partido da Social Democracia Brasileira (PSDB), partido diferente e opositor daquele que estava em nível nacional.

O artigo se divide da seguinte maneira: as duas primeiras partes do artigo compõem a fundamentação teórica. A primeira parte do trabalho trata sobre representação descritiva e como se tenta justificar porque ela é importante para a democracia, ao introduzir a representação de grupos, apresentando a forma como Pitkin, Phillips e Young trabalharam com essa ideia. Contudo, a noção de que representação justa implica representação proporcional, de acordo com características sociais, não deixa de ser controversa e a sua relação direta com uma responsividade por parte dos deputados é tratada na segunda parte do artigo.

Levando isso em consideração, realiza-se, na terceira parte, uma análise empírica na qual se busca perceber se existe ou não uma relação entre os tipos de representação descritiva e substantiva, a partir da análise da atuação de deputados que compuseram a 11a e 17ạ legislaturas da ALMG e que foram previamente classificados como semelhantes descritivamente à grupos que são constantemente excluídos de espaços de decisão política, partindo do que é definido como grupo marginalizado por Williams (1998). Segundo a autora, dinâmicas sociais, econômicas e políticas reproduzem padrões de desigualdade estrutural. Além dessas, características ligadas às funções ou status dados às pessoas na sociedade, produtos de características que não foram escolhidas, como sexo, raça ou idade, reforçam padrões de desigualdade. Para a 
Artigos | Relação entre representação descritiva e substantiva: o caso da Assembleia Legislativa de Minas Gerais (ALMG) (VIEIRA, Anne Karoline Rodrigues)

definição dos deputados que representam descritivamente os grupos subalternos foi realizada uma montagem do perfil dos deputados que compuseram as duas legislaturas estudadas - 11aㅡ e 17aa - e selecionados aqueles que possuíssem características semelhantes a esses grupos, como o fato de ser mulher, negro ou possuir uma escolaridade baixa. Para a definição da raça foi realizada a heteroclassificação das fotos dos deputados.

Na última parte do artigo são realizadas algumas considerações finais sobre a temática, dentre elas, aponta-se que o número de projetos apresentados por esses representantes é proporcionalmente pequeno quando comparado ao total de proposições para grupos minoritários que são propostos por todos os deputados que passaram por essas duas legislaturas. Levando-se a considerar que ser "um deles" não garante, automaticamente, que se atue de forma intensa "para eles".

\section{A presença como um aspecto na representação}

Pauta de movimentos sociais da década de $1960^{4}$ - que demanda, como ação política, a presença nos espaços de decisão -, a representação descritiva passa a ser debatida como alternativa para a promoção da responsividade a partir da similitude entre representantes e representados. Conceitos como "representação como relação diferenciada", "representação como mediação" e "política de presença", dentre outros, buscam apresentar os problemas enfrentados por determinados grupos de serem representados na política democrática e defendem o aumento da presença de grupos historicamente excluídos desses espaços (Dovi, 2012, p. 34).

Essa visão de representação surge, tendo como preocupação central a composição adequada da assembleia ${ }^{5}$. Segundo Pitkin (1967), este ponto de vista é mais claramente desenvolvido pelos teóricos da representação proporcional, que possuem como princípio a busca de uma Assembleia que reflita as várias divisões do eleitorado. Na representação descritiva, um corpo representativo deve ter uma correspondência

\footnotetext{
${ }^{4}$ Considera-se, entretanto, que os Antifederalistas já ressaltavam que os representantes deveriam ser semelhantes aos seus eleitores. Para eles, o fundamental era que os eleitos deveriam compartilhar circunstâncias, atitudes e sentimentos com aqueles que eles representavam, assim agiriam no interesse dos seus eleitores.
} 
Artigos | Relação entre representação descritiva e substantiva: o caso da Assembleia Legislativa de Minas Gerais (ALMG) (VIEIRA, Anne Karoline Rodrigues)

exata ou semelhante com aqueles que este corpo representa, refletindo as suas características sem distorção, fazendo presente o cidadão que está ausente. Uma concepção dessa ideia de representação afirma que um organismo representativo deve parecer uma cópia do organismo social em que se insere, de modo que deve conter membros dos grupos sociais óbvios na proporção em que eles são encontrados na sociedade (Young, 2000, p. 171).

Apenas a partir da discussão mobilizada por Stuart Mill, no final do século XIX, que se observa um tensionamento mais específico em relação a essa perspectiva. Mill (1981) mobiliza a ideia de representação proporcional para pensar além da representação majoritária. Há, então, um entendimento de que seria necessário garantir a liberdade, a propriedade e a expressão, tendo em vista que todos os cidadãos teriam acesso ao mesmo conjunto de direitos. Esse autor entende que a ideia de representação proporcional seria importante para assegurar que houvesse igual peso a todos os cidadãos no que se refere a definição da dinâmica da política. Seria necessário garantir que uma diversidade de grupos, com algum grau de expressão na sociedade, tivesse a possibilidade de falar em nome dos demais na representação política, sendo uma possibilidade de permitir a representação de minorias políticas.

Contudo, Mill (1981) defende o sistema proporcional não numa ideia de justiça social, mas para garantir um cenário mais propício para deliberação e aproximação da verdade. Não sendo uma perspectiva ideológica, mas pragmática, pela ideia de que, através do debate e deliberação nesse espaço público, o parlamento conseguiria se aproximar do que viria a ser a compreensão sobre a realidade da sociedade, a verdade sobre a melhor forma de organizar a mesma.

Em contrapartida, Pitkin mostra que na representação descritiva "O que distingue uma legislatura representativa de outro grupo qualquer de pessoas é sua correspondência precisa, de parte a parte, com a maioria da população pela qual ela é responsável" (Pitkin, 1979, p. 15). Portanto, o que importa nessa perspectiva são as características dos representantes, quem eles são, criando uma correspondência, um mapa preciso da nação, já que a casa legislativa deve formar um microcosmo da sociedade. Diferenciando-se da representação formalista, por defender que o representante "standing for" por alguém ausente através de alguma correspondência de características. Com isso, "[...] o que parece importante é menos o que a legislatura 
Artigos | Relação entre representação descritiva e substantiva: o caso da Assembleia Legislativa de Minas Gerais (ALMG) (VIEIRA, Anne Karoline Rodrigues)

faz do que como ela é composta" (Pitkin, 1967, p. 61) ${ }^{6}$, o que qualifica uma pessoa para ser representante é a sua representatividade. Com isso, a voz do representante deve ser fiel aos interesses dos seus representados.

Contudo, Pitkin (1967) critica o zelo dos defensores da representação descritiva pela composição do legislativo, deixando de lado a importância da atividade parlamentar. Quando os representantes são ligados à representação simbólica ou à representação descritiva, eles são vistos como objetos inanimados e não é considerada a sua atividade como representante, já que o que importa é como ou o que eles são. 0 que os representantes farão depois não se discute, não pensando a representação como atividade e sim como uma forma de substituir (Pitkin, 1967). Segundo a autora, a promessa de correspondência é impossível de se realizar e as normas de representação da sociedade podem demandar diferenças especiais ao invés de identidade, apontando que, nas democracias modernas, os representantes têm sido escolhidos por serem de classe superior. Além do mais, o grau de precisão não garante, de forma automática, o grau de similaridade da ação.

Nessa dimensão, não haveria responsividade ou a preocupação com a ação do representante. De tal modo, não faz sentido falar sobre suas obrigações e suas ações, fundamentos importantes para Pitkin (1967), pois são eles que garantem o governo representativo. Portanto, a visão substantiva - o que ele faz - seria o que melhor definiria a representação para a autora.

Teóricas feministas, em especial Phillips (2001), rebatem a crítica feita por Pitkin à representação descritiva, mostrando que a composição do parlamento e a ação do representante não estão separadas. Preocupadas com a pouca presença dos grupos historicamente excluídos, mostram que a presença desses grupos, no campo político, pode levar à promoção dos seus interesses. Esse argumento retoma a ideia apresentada por Phillips (2001) de política de presença que valoriza quem o representante é. A importância dada por Phillips à política de presença, ao invés do foco exclusivo na política de ideias, como realizado pelos teóricos liberais, será discutida no tópico a seguir.

\footnotetext{
${ }^{6}$ Tradução livre do ingles: "[...] what seems important is less what the legislature does than how it is composed" (Pitkin, 1967, p. 61).
} 
Artigos | Relação entre representação descritiva e substantiva: o caso da Assembleia Legislativa de Minas Gerais (ALMG) (VIEIRA, Anne Karoline Rodrigues)

\section{Phillips e a importância da presença para a representação}

Phillips (2011) defende a representação de grupos por acreditar que a composição das assembleias está enviesada em direção a categorias que acabam se desviando das características do eleitorado, dando mais poder a um determinado grupo, gerando problemas para a democracia. Segundo a autora, não é possível ver os grupos subalternos nos legislativos, na mesma proporção que se vê na sociedade, por haver interesses estabelecidos e estruturas de poder que sustentam os grupos privilegiados. Dessa forma, os grupos oprimidos precisam de mais oportunidades para a formação de políticas públicas que possam garantir a mudança dessa realidade (Phillips, 1998).

Esta autora aponta alguns argumentos que mostram a necessidade de representação descritiva dos grupos excluídos. O primeiro, o "argumento modelo", mostra que membros de grupos desfavorecidos se beneficiam ao terem representantes desses grupos ocupando posições de poder. O segundo argumento, chamado de "argumento de justiça", assinala que a representação descritiva compensa injustiças sofridas por certos grupos, tanto históricos quanto atuais, que determinam padrões de desigualdade. O terceiro argumento baseia-se no que Phillips chama de "interesses esquecidos", o qual aponta que a representação descritiva permite que os interesses e perspectivas dos grupos excluídos, anteriormente esquecidos, entrem na agenda política.

Tendo como referência a representação descritiva e os limites da política de ideias de Pitkin (1967) - que foca nos interesses dos representados -, Phillips (2001) desenvolve o conceito de política de presença. A autora também parte da ineficiência da responsividade e da accountability, que apresentam apenas a eleição como oportunidade de autorização dos representantes, impedindo a possibilidade de ação política por parte dos cidadãos. A necessidade da presença política foi deixada de lado pelos liberais, uma vez que a diferença é considerada, por eles, em termos de diversidade intelectual, sem importar quem representa as ideias. Contudo, a experiência compartilhada pode servir de garantia para a execução da responsividade, desde que não haja uma inversão simples da política de ideias para uma política pura de presença (Phillips, 1998). A presença política importa, porque as estruturas de poder impedem a entrada de determinadas perspectivas. Importa, ainda, para a 
Artigos | Relação entre representação descritiva e substantiva: o caso da Assembleia Legislativa de Minas Gerais (ALMG) (VIEIRA, Anne Karoline Rodrigues)

transformação da agenda política, fundamental para os grupos marginalizados, em sociedades com estruturas de poder que negam a importância de perspectivas excluídas (Phillips, 1998).

Phillips (1998) afirma que uma representação adequada se refere cada vez mais à representação de diferentes grupos sociais que compõem a sociedade, garantindo a igualdade política. Contudo, ela tenta se distanciar de fundamentos estatísticos entre representantes e representados, não defendendo que as pessoas sejam representadas apenas como grupos - a ideia mais substancial de representação descritiva - pois acredita na necessidade de se representar crenças que, segundo a mesma, são variadas e individuais (Phillips, 2011). A autora não fala em representação proporcional, mas em representação daqueles que são excluídos, acreditando que, ao aumentar a quantidade de representantes de grupos desfavorecidos, modificará a base sobre a qual as políticas são estabelecidas (Phillips, 1998, p. 190).

Uma das objeções em relação à política de presença é que ela pode impedir a formação de alianças ao promover uma assembleia tão diversificada. Enquanto a política de ideias, ao contrário, permitiria o debate entre aqueles com diferentes opiniões e perspectivas. Mesmo que a política de ideias não garanta a presença daqueles grupos excluídos, não é possível descartá-la da discussão sobre representação e considerar apenas a política de presença (Phillips, 2001, p. 289). Phillips (2001) busca não promover a substituição da política de ideias pela de presença, mas a complementação e correção dos vieses da primeira pela incorporação da segunda, com a inclusão de mecanismos descritivos (Miguel, 2014, p. 207), não descartando a necessidade de supervisão dos representantes através da accountability e da autorização, e sem recusar totalmente a política de ideias.

Contudo, Phillips não traz respostas à crítica apresentada por Pitkin (1967), de que existe um problema na representação descritiva, uma vez que pode haver um representante daquele grupo, mas, a partir da visão substantiva, não realizar efetivamente um ato em favor do grupo. Ainda, a autora passa a ser acusada de defender uma identidade muito marcada. Mas, ao argumentar que aquele que não está representado demanda presença política, Phillips (2011) passa a adotar o conceito de perspectiva social, substituindo o de identidade, uma vez que o primeiro se mostra menos fechado e mais relacional (Miguel, 2014, p. 207). Além disso, o conceito de 
Artigos | Relação entre representação descritiva e substantiva: o caso da Assembleia Legislativa de Minas Gerais (ALMG) (VIEIRA, Anne Karoline Rodrigues)

perspectiva pode escapar dos problemas relacionados com a identidade, dentre eles o essencialismo. Young entra na discussão de perspectivas, mostrando que, na verdade, não existe identidade igual a interesses, mas perspectivas, que são pontos de partida para a construção de políticas.

\section{Perspectivas como pontos de partida para as políticas}

Young (2006, p. 140) assinala que a desigualdade socioeconômica produz desigualdade política. Assim, as pessoas que sofrem com essas desigualdades podem não ter os seus interesses e perspectivas bem representados. A autora critica o ideal liberal de igualdade, por pregar a homogeneidade entre os cidadãos, o que acaba excluindo aqueles que não se enquadram no padrão de cidadania racional do liberalismo - o qual pressupõe a existência de um tipo universal de cidadão. Criticando a possibilidade de princípios imparciais de justiça e fazendo uma defesa da representação dos grupos oprimidos, Young aponta que "[...] um público democrático deve fornecer mecanismos para o efetivo reconhecimento e representação das vozes e perspectivas distintas daqueles que constituem grupos que são oprimidos ou desfavorecidos" (1990, p. 184$)^{7}$. Destarte, inclusão para Young (2000) significa reconhecer as diferenças e divisões sociais, encorajando os grupos a explanarem as suas demandas e perspectivas, não sendo simplesmente a garantia da igualdade formal e abstrata na forma de cidadania. Young traz essa discussão a partir de um questionamento sobre a justiça, mas de um ponto de partida diferente de Pitkin (1967) que está mais preocupada com os mecanismos de controle político. O que não quer dizer que Young não considera os controles representativos, mas os coloca em segundo plano no seu debate sobre representação.

Para Young (2006), a representação política é necessária, mas impossível. Ela é necessária no contexto em que se tenha uma estrutura social com um número muito elevado de pessoas em que é importante organizar uma estrutura de transmissão de significados entre os interesses da sociedade e a dimensão de tomada de decisão

\footnotetext{
7 Tradução livre do inglês: "[...] a democratic public should provide mechanisms for the effective recognition and representation of the distinct voices and perspectives of those of its constituent groups that are oppressed or disadvantaged" (Young, 1990, p. 184).
} 
Artigos | Relação entre representação descritiva e substantiva: o caso da Assembleia Legislativa de Minas Gerais (ALMG) (VIEIRA, Anne Karoline Rodrigues)

política. Porém, para a autora, dificilmente aquele que se coloca como representante vai representar efetivamente a posição de um indivíduo, remetendo ao que é colocado por Pitkin (1967). Uma vez que a representação é múltipla, não opera apenas de acordo com o interesse de um único indivíduo, mas de uma diversidade de pessoas. Então, a chance de um representante estar no lugar de milhares e falar em nome de todos é, do ponto de vista lógico, impossível. Porém, Young (2006) defende que o problema está na base em como se define a relação identitária entre representante e representado.

Para ela, representação é conceituada na forma de différance, a fim de garantir a manutenção das pluralidades sem a unificação das identidades em uma só. Isso dissolve o paradoxo de que apenas uma pessoa representa opiniões e experiências de tantas outras, pois não há uma vontade única a ser representada, tampouco um representado como dado, ao qual o representante deve espelhar (Young, 2006). Já que o representante é diferente dos seus eleitores, o que garantirá uma boa democracia é o quanto essas posições diferenciadas estejam conectadas por meio de relacionamentos de prestação de contas e autorização, não como o modelo formal, mas como algo contínuo e processual na construção destes representados.

Mesmo que os indivíduos possuam experiências diferenciadas com relação aos eventos sociais, aqueles situados em posições sociais semelhantes teriam maior probabilidade de possuírem os mesmos "pontos de vista". Assim, mesmo com a ideia de representação diferenciada, a autora vai continuar a defender a política descritiva, mas o faz de maneira diferente, a partir do conceito de perspectiva social. Esse conceito sugere, então, que "Agentes que estão posicionados de forma semelhante, possuem constrangimentos ou habilitações semelhantes, modos particulares de expressão e afinidade, nas relações sociais" (Young, 2000, p. 100) ${ }^{8}$, que devem ser incluídas no meio político, a partir da representação de grupos.

Ao colocar a perspectiva como central, Young (2000) fala que não se trata de compartilhar atributos - no sentido de Pitkin - ou identidade - como Phillips elaborava -, é compartilhar uma experiência com muitas pessoas. Assim, os indivíduos constroem as suas identidades de acordo com o posicionamento do grupo social, não possuindo uma identidade específica, como se deduz a partir dos argumentos de Phillips. Para

\footnotetext{
8 Tradução livre do inglês: "Agents who are similarly positioned experience similar constraints or enablements, particular modes of expression and affinity, in social relations" (YOUNG, 2000, p. 100).
} 
Artigos | Relação entre representação descritiva e substantiva: o caso da Assembleia Legislativa de Minas Gerais (ALMG) (VIEIRA, Anne Karoline Rodrigues)

Young (2006), a representação de grupos pluralizaria a representação, por não considerar uma perspectiva social unificada, na qual todos os indivíduos posicionados de forma similar se expressariam, condicionados sobre a mesma perspectiva.

Young (2006) mostra como a presença está intrinsecamente ligada a algumas ideias, por meio do conceito de perspectivas sociais. Defende que os grupos são melhor representados por aqueles que compartilham as mesmas perspectivas, já que elas são experiências e trajetórias de vida, "[...] ponto de vista que os membros de um grupo mantêm sobre os processos sociais em função das posições que neles ocupam" (Ibid, p. 164). Cada grupo social, ao se diferenciar por relações estruturais de privilégio e desvantagem, vive experiências que Ihes confere interpretações sobre sua situação e a relação com os demais grupos, desenvolvendo perspectivas similares, devido ao posicionamento na estrutura.

Críticas em relação às perspectivas recaem, sobretudo, em relação à conexão entre preferências e identidades, em relação à responsividade e ao risco da essencialização das diferenças (Phillips, 2009). As desigualdades sociais e os conflitos de interesses podem não se dissipar com a inclusão das perspectivas e, com isso, a inclusão de grupos na política deve vir da defesa da justiça, na qual a presença dá acesso ao capital necessário para o exercício do poder. Tentando responder aos problemas de essencialização, Young (2000) aponta que, na realidade, os membros desses grupos possuem diferentes interesses e posicionamentos ideológicos.

Após essa breve passagem em torno do que foi debatido sobre a representação descritiva, percebe-se que Pitkin (1967) está mais focada nos componentes estratégicos para possibilitar que o eleitorado, de forma geral, afete a estrutura política, e em como melhorar a qualidade da representação política através das eleições. Nesse sentido, Phillips vai perceber o efeito de desprezar a dimensão descritiva da representação, valorizando, a partir disso, a mobilização em torno das identidades. Para a autora, independente de Pitkin discutir a representação geral, tem grupos apontando que isso não dá conta, não sendo possível manter a forma como a dinâmica opera apenas a partir das eleições. Phillips justifica isso através da identidade, mas essa concepção vai ter dificuldade para poder pensar a representação política eleitoral, por acabar promovendo uma universalização. Nesse ponto, Young se mobiliza, preocupada com o caráter homogeneizante tanto do liberalismo, como da abordagem identitária. Por isso, 
Artigos | Relação entre representação descritiva e substantiva: o caso da Assembleia Legislativa de Minas Gerais (ALMG) (VIEIRA, Anne Karoline Rodrigues)

Young vai considerar a ideia de perspectiva social para justificar a definição dos representantes. Cabe-nos agora discutir a relação entre essa dimensão descritiva da representação e a apresentação de demandas para grupos minoritários, considerando a dimensão substantiva.

\section{Representação descritiva e substantiva: uma relação possível?}

Parte da literatura argumenta que o aumento na representação descritiva dos grupos subalternos, resultaria em um aumento na representação substantiva deles. Dentre os modelos de representação apresentados por Pitkin (1967) está o de representação substantiva, no qual o representante oscila entre o mandato imperativo e independente. A teoria do governo representativo caminhou para uma relação entre esses dois polos - independência e delegação. No mandato imperativo o representante é um delegado, que deve agir no interesse do constituinte, expressando a vontade da sua base. No mandato livre o representante toma decisões de forma independente, sobre a coisa certa a se fazer; ele é um agente livre, um especialista.

Para que o conceito de representação seja adequado, Pitkin (1967) propõe que ele deva ser pensado como atividade e que se refira à substância do que é feito. A atividade da representação deve ser definida em termos do que o representante faz e como ele faz. Assim, a autora constrói o conceito de representação como uma atividade do representante, que tem como objetivo atuar substantivamente no interesse do representado, de modo responsivo a ele. A presença é algo que precisa ser construída pela ação do representante, uma vez que a representação existe quando as pessoas se tornam presentes na ação governamental.

Considerando uma atuação direcionada, a representação descritiva foi apresentada, na seção anterior, com os representantes mais propensos a agir responsivamente em nome dos grupos subalternos. Contudo, gradualmente, a natureza dessa operacionalização se tornou objeto de intenso escrutínio (Severs, 2010). Alguns estudos criticam esse pressuposto por ignorar a diferença entre os membros desses grupos e desconsiderar o potencial de outros representantes como atores agindo em nome deles. Ter representantes de minorias sociais pode, então, não ser suficiente para a garantia da responsividade dos mesmos e pertencer a um grupo pode não significar 
Artigos | Relação entre representação descritiva e substantiva: o caso da Assembleia Legislativa de Minas Gerais (ALMG) (VIEIRA, Anne Karoline Rodrigues)

diretamente expressar suas demandas. Segundo Severs (2010), a ideia de que ser "um dos nossos" iria promover automaticamente lealdade aos "nossos" interesses, foi desconsiderada por pesquisas empíricas, indicando que nem todos os representantes desses grupos procuram promover os seus interesses, enquanto outros o fazem.

Muitos autores, dentre eles Young (2006) e Williams (1998), chegam a reconhecer que membros de grupos desfavorecidos nem sempre representam bem os interesses de seus grupos. Essas autoras chegam a afirmar que esses representantes podem marginalizar ainda mais esses grupos de interesse. Além do mais, os interesses desses grupos podem estar dispersos e/ou serem alvos de disputa dentro dos próprios segmentos minoritários. O caso LGBT é emblemático, uma vez que um conjunto de questões que remetem a esse grupo estão em disputa, seja em torno de um sentido comum ao coletivo, seja em torno do que deve ser prioridade na agenda pública. Contudo, isso também vale para outros segmentos minoritários socialmente. Esses autores abordam essa questão por considerarem que um grupo marginalizado é composto por visões de mundo diversas, não podendo ser considerado homogêneo. Dessa forma, ao contar com poucos representantes, esses grupos não dariam conta de expressar as posições relevantes que existem em meio a eles.

Com isso, Dovi (2012) assevera que a presença dos membros desses grupos pode não ser suficiente para uma representação justa dos seus interesses, mesmo que isso seja necessário. Segundo a autora, representantes descritivos "Podem avançar os interesses, opiniões e perspectivas de constituintes relativamente privilegiados. Alguns representantes descritivos podem vir do grupo certo, mas não se comprometerem a fazer avançar as preocupações e os interesses de seu grupo" (Dovi, 2012, p.44) ${ }^{9}$.

Mansbridge (1999) também aponta para o fato de que a presença de membros desses grupos nos parlamentos não resulta diretamente em uma atuação voltada para eles. Diversos fatores interferem na capacidade desses representantes de atuarem em favor dos interesses de mulheres ou negros, até mesmo, "Alguns membros de grupos desfavorecidos ressentem, denunciam e rejeitam de todo o coração qualquer obrigação

\footnotetext{
${ }^{9}$ Tradução livre do inglês: "They might advance the interests, opinions, and perspectives of relatively privileged constituents. Some descriptive representatives might come from the right group, but not be committed to advancing the concerns and interests of their group" (Dovi, 2012, p.44).
} 
Artigos | Relação entre representação descritiva e substantiva: o caso da Assembleia Legislativa de Minas Gerais (ALMG) (VIEIRA, Anne Karoline Rodrigues)

particular para com grupos desfavorecidos" (Mansbrigde, 2003, p. 42) ${ }^{10}$, consequentemente, nem todos serão bons representantes para esses grupos. Assim, a crítica aos representantes descritivos repousa na capacidade deles em serem responsivos.

Entretanto, parte da literatura sobre o assunto (Orsato e Gugliano, 2012; Pinheiro, 2007) - que muitas vezes é voltada apenas para a discussão em relação ao gênero - aponta que os representantes desses grupos sub-representados direcionam a sua atuação parlamentar para temas reconhecidamente tidos como específicos desses grupos. Porém, isso pode ser visto como uma estratégia dos parlamentares de voltarem sua atuação para temas com os quais já possuem uma maior afinidade e conhecimento ou pode ser tratado como um insulamento desses parlamentares em temas que, muitas vezes, não possuem visibilidade no campo político, reproduzindo, assim, a exclusão social vista em outras áreas da sociedade.

Pinheiro (2007), quando observa os projetos de autoria das deputadas federais do pós-constituinte, percebe que são aprovadas matérias que não possuem muito prestígio, podendo-se afirmar que as deputadas, apesar de suas diferenças ideológicas e de classe, ainda pautam a sua atuação de acordo com o papel que lhes é determinado na sociedade. Assim, a questão simbólica pesa sobre elas e pode pesar também sobre outros representantes de grupos sub-representados, tendo como consequência o isolamento desses representantes em papéis de menor prestígio e o silenciamento de suas vozes dentro da casa legislativa.

Esses temas que ficam a cargo das mulheres nos legislativos acabam reforçando os estereótipos de gênero construídos socialmente. Às vezes, esse é o único tema o qual elas podem tratar nesses espaços (Miguel e Feitosa, 2009), insulando-as e deixando aos homens os temas mais valorizados. É o reforço de um essencialismo que atribui à mulher o papel de cuidar dos outros, reforçando as atribuições sexuais vistas em outros domínios da sociedade, negando-a o poder de possuir interesses próprios.

Deve-se ressaltar que, apesar dos exemplos apresentados apontarem para uma questão quase que exclusivamente de gênero, pode-se afirmar que isso se reproduz em outros tipos de minorias, como os negros, os trabalhadores (manuais ou

\footnotetext{
10 Tradução livre do inglês: "Some members of disadvantaged groups resent, denounce, and reject wholeheartedly any particular obligation to disadvantaged groups" (Mansbrigde, 2003, p. 42).
} 
Artigos | Relação entre representação descritiva e substantiva: o caso da Assembleia Legislativa de Minas Gerais (ALMG) (VIEIRA, Anne Karoline Rodrigues)

subqualificados), dentre outras, que podem se ver contidas nas áreas de atuação as quais refletem o seu perfil descritivo, restringindo a sua atuação na arena da produção de leis. Phillips (2011) argumenta que isso implica que apenas aqueles que possuem experiência podem dizer de forma legítima sobre determinado tema, ferindo valores republicanos.

Ao se defender exclusivamente a política de presença nos trabalhos parlamentares, pode se estabelecer uma divisão social que reforça, dentro da casa legislativa, a divisão social existente historicamente na nossa sociedade, ao se determinar que os representantes estejam mais aptos a falar pelos grupos vulneráveis, por aqueles que são sistematicamente esquecidos e ainda de modo geral, como se fizessem parte de um grupo homogêneo. A justa representação não se dá, contudo, apenas com a presença dos membros dos grupos marginalizados, nos espaços de formulação de políticas, mesmo que essa presença seja necessária.

Foi apresentado aqui a visão de que membros dos grupos minoritários estejam presentes no parlamento para que seja garantida a responsividade para esses grupos. Abandonando, desta forma, a visão liberal de que a partir das eleições todos estariam presentes, sem considerar as desigualdades e as diferenças sociais. Contudo, mostrouse que essa pode não ser uma relação direta, uma vez que alguns parlamentares podem não querer atuar para o grupo o qual ele tem uma relação descritiva, ou até mesmo, a atuação responsiva aos temas afeitos às minorias pode esconder um insulamento em questões que manteriam esses grupos isolados no legislativo. As pesquisas na área mostram que a relação entre presença de grupos e defesa de interesses ou de políticas para seus pares é contingente e não necessária. Compete-nos agora perceber como isso ocorre no caso da ALMG e das duas legislaturas escolhidas para o estudo. A ideia é avaliar por quem certos interesses ou políticas de minorias são introduzidos, sem relacioná-las, necessariamente, como sendo congruentes com o interesse do representado.

\section{A responsividade às minorias na ALMG}

Como Griffin et al. (2012) colocam, a expectativa de que os representantes atuem sobre as preferências de seus eleitores é um valor normativo e pressuposto 
Artigos | Relação entre representação descritiva e substantiva: o caso da Assembleia Legislativa de Minas Gerais (ALMG) (VIEIRA, Anne Karoline Rodrigues)

empírico firmado há muito tempo na Ciência Política. As posições dos legisladores na Casa podem ser influenciadas pelas preferências dos eleitores, dos grupos de interesse e pelo partido. Contudo, Carnes (2012, p. 10) e algumas autoras apresentadas no decorrer deste trabalho acreditam que elas podem ser influenciadas também pelo próprio julgamento dos legisladores, por suas características pessoais, experiência ou identificação com algum grupo social, que podem inspirar as suas atuações. Considerando essa proposição, será apresentada a análise da atuação, para os grupos minoritários, dos deputados enquadrados por essa pesquisa como representantes desses grupos, integrantes da $11^{\text {a }}$ e 17 ạ legislaturas da ALMG. Ainda, são analisados quais desses grupos contam com um maior atendimento às suas demandas e aqueles que possuem uma responsividade baixa.

\section{Descrição metodológica}

Para esta pesquisa foram realizados levantamento quantitativo e análise qualitativa da produção legislativa no período escolhido - durante a 11 a e 17 a legislaturas -, a partir de um recorte temático das proposições legislativas, nos quais foram selecionados projetos ligados à representação de minorias. A análise e tabulação desses projetos foram realizadas com a ajuda do software científico SPSS.

Os projetos voltados para os grupos minoritários foram selecionados a partir da análise de conteúdo temático dos projetos apresentados pelos deputados, os quais se encontram disponíveis no site da ALMG, sendo assim a fonte de dados utilizada para os projetos é a própria Assembleia Legislativa. As ementas de todos os projetos foram lidas e aqueles que continham alguma referência aos grupos minoritários, eram selecionados e enquadrados em categorias relacionadas a quais grupos eles correspondiam, não sendo realizada a leitura do conteúdo integral deles.

Em se tratando de direitos de minorias, muitos projetos podem ser propostos e não comporem a agenda de votação, como será comprovado a seguir, devido aos constrangimentos do processo de encaminhamento de propostas. Assim, os projetos podem falar mais da atuação dos deputados do que a votação e/ou aprovação de leis. Dessa forma, mostra-se a importância de se analisar os projetos e não apenas aquelas 
Artigos | Relação entre representação descritiva e substantiva: o caso da Assembleia Legislativa de Minas Gerais (ALMG) (VIEIRA, Anne Karoline Rodrigues)

políticas que se tornaram norma jurídica, uma vez que a apresentação de projetos também diz muito em relação ao processo legislativo.

Não são desconsiderados, entretanto, possíveis viesses que possam surgir ao se analisar apenas os projetos. $O$ deputado pode apresentar projetos que apenas garantam benefícios eleitorais, sem necessariamente se identificar com aquilo que está propondo. Ainda, os representantes desses grupos podem se utilizar de outros repertórios além da apresentação de projetos, como fazer pressão junto aos seus colegas ou à impressa, recorrer ao Judiciário, entre outros. Além disso, os projetos voltados para minorias podem, muitas vezes, serem elaborados sem que esses grupos participem, podendo ser diferentes das suas demandas, além de outras questões que também podem enviesar a análise dos projetos. Ainda, é importante notar que existe toda uma atuação fora do parlamento, que pode se dar junto às secretarias de Estado, as quais podem render retornos mais diretos aos eleitores (Bezerra, 1999). E, para além da burocracia estadual, também há um trabalho de articulação com os representantes no Congresso Nacional.

Mas, a análise exclusiva sobre os projetos voltados para minorias se dá, uma vez que os grupos minoritários acabam possuindo demandas específicas que os afetam cotidianamente. A partir dessas demandas, a pesquisa se concentra em políticas sobre as quais mais se ressaltam as diferenças de representação substantiva.

Para a montagem do perfil dos deputados e a sua separação naqueles que representavam descritivamente minorias sociológicas, foi utilizado dados secundários. Foi montado o perfil de um total de 154 deputados estaduais, que estiveram presentes nas duas legislaturas já mencionadas, chegando a 11 deputados que se enquadravam na proposta da pesquisa, considerando a raça - se fazendo uso da heteroclassificação , sexo e escolaridade. As fontes de dados foram o Tribunal Superior Eleitoral (TSE) e, mais uma vez, o site da ALMG, onde consta um perfil resumido dos deputados. Para a análise estatística se fez uso do software SPSS. Esta montagem do perfil serve para observar se ser "um deles" significa ou não atuar "para eles".

\section{Análise dos resultados}

Primeiramente, buscou-se perceber como ocorreu a atuação para as minorias, considerando todos os deputados que compuseram as duas legislaturas. A partir da 
Artigos | Relação entre representação descritiva e substantiva: o caso da Assembleia Legislativa de Minas Gerais (ALMG) (VIEIRA, Anne Karoline Rodrigues)

coleta de dados através da ALMG, é possível perceber que as proposições voltadas para os grupos minoritários na Casa, no período analisado, chegam a 11,39\% do total de projetos elaborados pelos deputados. Esse número é considerado pequeno, uma vez que, além de comporem boa parte da população mineira, são grupos que muitas vezes possuem suas manifestações democráticas submetidas a uma marginalização e lidam com desigualdades socioeconômicas. Além disso, a grande parte desses projetos referese à legislação considerada de pouca relevância, como a declaração de utilidade pública $^{11}$ e doação e reversão de imóveis, o que pode não influenciar de forma tão incisiva a vida dos membros desses grupos.

Tabela 1

Número de proposições por legislatura

\begin{tabular}{|c|c|c|c|}
\hline Legislatura & $\begin{array}{c}\text { Quantidade de } \\
\text { proposições }\end{array}$ & $\begin{array}{c}\text { Proposições } \\
\text { voltadas para } \\
\text { minorias }\end{array}$ & Proporção \\
\hline $\begin{array}{c}\text { 11 a legislatura } \\
\text { (1987-1991) }\end{array}$ & 1387 & 154 & $11,10 \%$ \\
\hline $\begin{array}{c}17 \text { a legislatura } \\
\text { (2011-2015) }\end{array}$ & 4784 & 549 & $11,48 \%$ \\
\hline Total & 6171 & 703 & $11,39 \%$ \\
\hline
\end{tabular}

Fonte: Site da ALMG. Elaboração própria.

Quando se analisam as duas legislaturas separadamente, percebe-se que proporcionalmente, a quantidade de projetos voltados para os grupos, objeto da pesquisa, não se alterou como se poderia esperar. A 11a legislatura, apesar de ter se aproximado consideravelmente da população mineira, ouvindo as suas demandas, a partir da Constituinte e do início da institucionalização da participação, apresenta apenas $11,10 \%$ de proposições, $0,38 \%$ a menos do que a 17 ạ legislatura $(11,48 \%)$ que conta com mais canais de participação da população e consequentemente com uma maior abertura para se captar as demandas dos mineiros. Deve-se observar, contudo, que a 17a legislatura apresenta um número de projetos para minorias maior que a 11a - são 549 projetos em comparação a 154 proposições. Isso é reflexo de um maior

\footnotetext{
${ }^{11}$ São projetos que visam o reconhecimento, por parte do poder público, da prestação de serviços à sociedade, ou no caso, à alguma minoria, por uma determinada instituição. Não sendo considerado de grande utilidade por não ser um projeto que promova diretamente algum benefício a essa população.
} 
Artigos | Relação entre representação descritiva e substantiva: o caso da Assembleia Legislativa de Minas Gerais (ALMG) (VIEIRA, Anne Karoline Rodrigues)

número geral de proposições apresentadas nesse período, são 4.784 propostas em relação a 1.387 projetos apresentados pelos deputados da 17a para a 11a legislatura.

Quando se analisa a situação final dessas proposições, um fato interessante é observado, uma vez que a maioria $(51,6 \%)$ das propostas se transforma em norma jurídica, podendo considerar que as políticas voltadas para os grupos minoritários encontram alta aceitação na ALMG. Esse índice de projetos para as minorias sociais transformados em lei é mais significativo ainda ao ser comparado com o total de projetos que se tornam norma jurídica, $41,14 \%$. Mostrando que os projetos para minorias têm uma aprovação maior ao ser comparado com o total de proposições apresentas pelos deputados mineiros. Mas deve ser ressaltado mais uma vez que, por ser a maioria das políticas declarações de utilidade pública, doação e reversão de imóveis, elas encontram maior facilidade para passar pelas barreiras da Casa e se transformar em lei, mas não serem tão úteis para a população, além de atuarem pouco nos privilégios e nas estruturas desiguais da sociedade. Ao se analisar a situação da outra metade dos projetos, percebe-se que 48,3\% deles não chegam ao plenário para votação, contudo, índice bem menor quando se observa o total de proposições que não foram votadas na ALMG, 58,86\%.

Gráfico 1

Situação das proposições voltadas para minorias na 11a legislatura

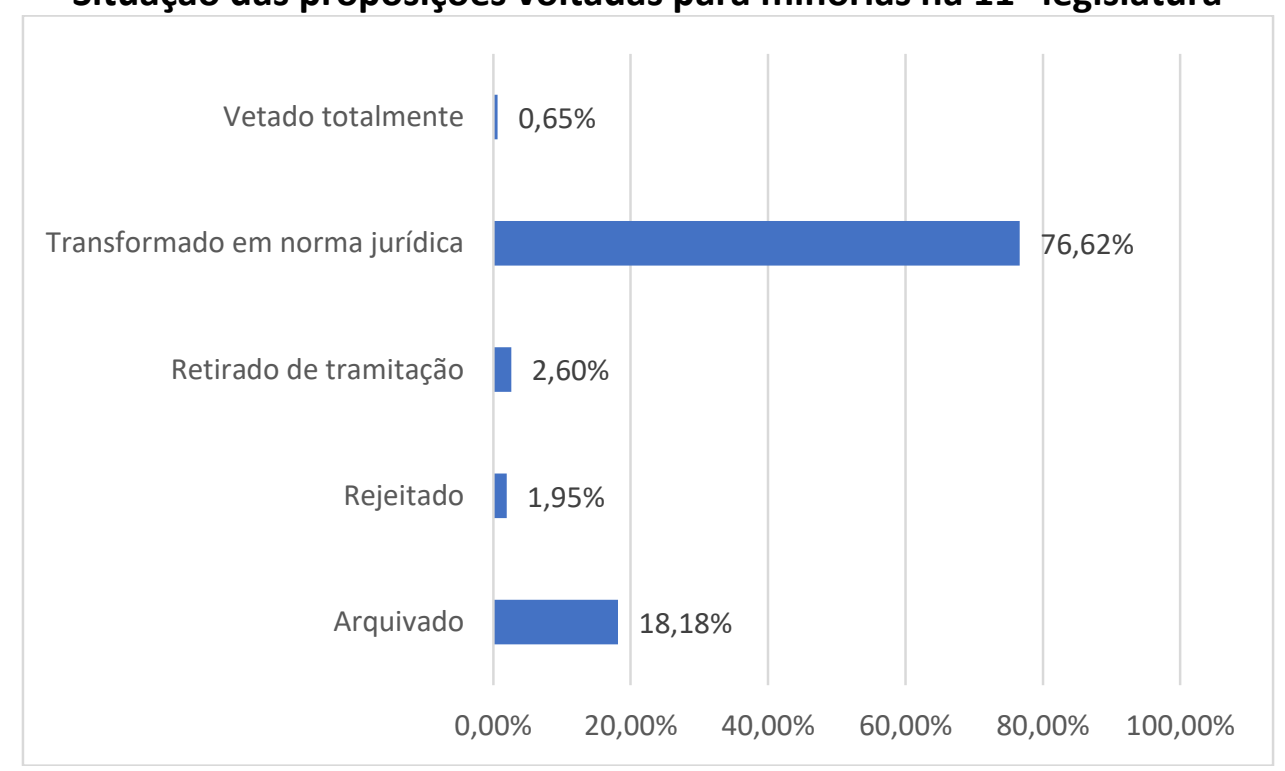

Fonte: ALMG. Elaboração própria. 


\section{Gráfico 2}

Situação das proposições voltadas para minorias na 17ạ legislatura

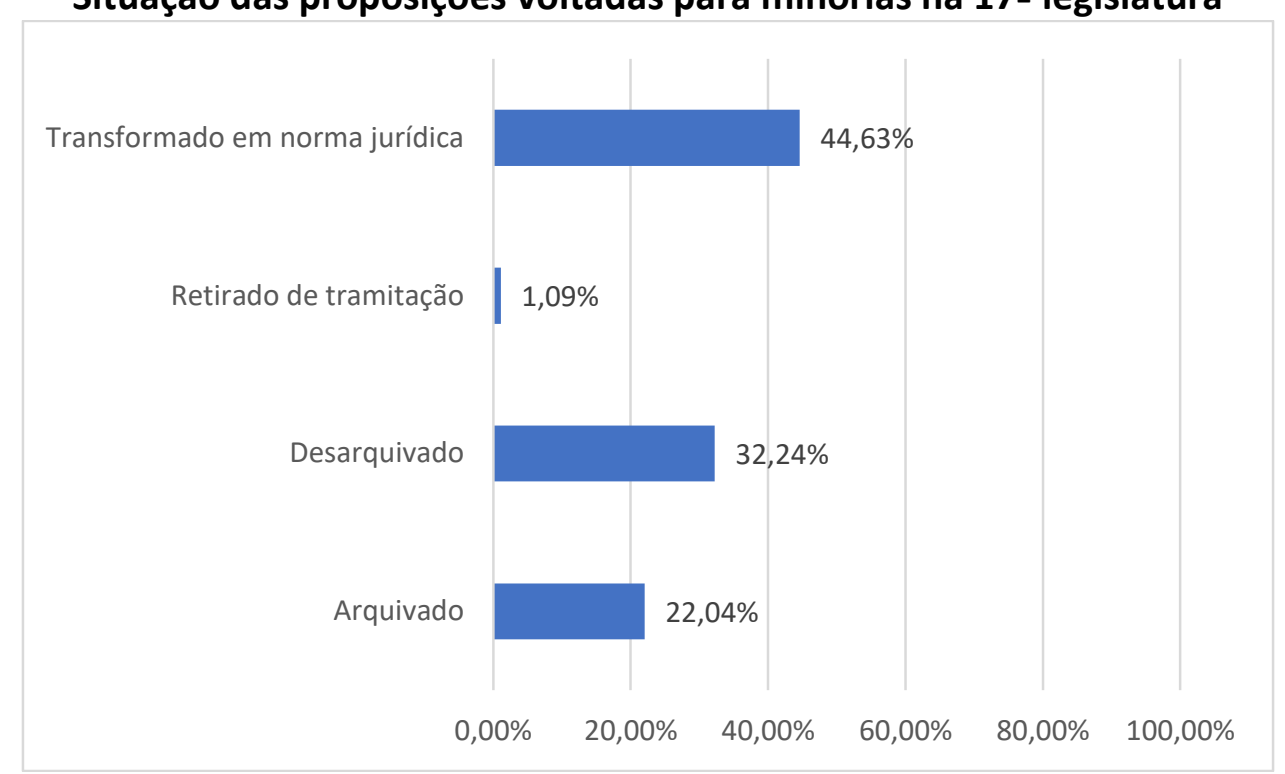

Fonte: ALMG. Elaboração própria.

Para a análise da atuação dos deputados que representavam descritivamente grupos subalternos, partiu-se, inicialmente, da montagem do perfil dos 154 deputados que compuseram as duas legislaturas analisadas e da seleção daqueles que se enquadravam no perfil aqui esperado. Sendo assim, apenas 11 foram enquadrados entre aqueles que representavam mulheres, negros ou pessoas com baixa escolaridade ${ }^{12}$ - no caso, que possuíam apenas o ensino fundamental completo -, por possuírem ao menos uma dessas características em seu perfil. A baixa representação descritiva desses grupos na ALMG pode ser uma das explicações possíveis para a baixa mobilização para pautas para eles. Esse ponto é exatamente o que motiva a discussão mobilizada por Young e Williams contra a interpretação de Pitkin.

Partindo-se para a análise dos projetos propostos exclusivamente por esses deputados, percebeu-se que, no total, eles apresentaram 79 projetos para as minorias sociais, representando $1,28 \%$ do total de projetos apresentados durante as duas legislaturas. Não pode ser desconsiderado, contudo, a baixa quantidade desses representantes neste legislativo, o que pode levar ao baixo número de projetos encontrados.

12 Não é desconsiderado, entretanto, que baixa escolaridade não implique, necessariamente, em marginalização. Um empresário do setor agropecuário pode gozar de uma condição de vida muito elevada a despeito de sua formação. 
Tabela 2

Número de proposições dos representantes descritivos por legislatura

\begin{tabular}{|c|c|c|c|}
\hline Legislatura & $\begin{array}{c}\text { Quantidade de } \\
\text { proposições }\end{array}$ & $\begin{array}{c}\text { Proposições } \\
\text { voltadas para } \\
\text { minorias }\end{array}$ & Proporção \\
\hline $\begin{array}{c}\text { 11a legislatura } \\
\text { (1987-1991) }\end{array}$ & 77 & 13 & $16,88 \%$ \\
\hline $\begin{array}{c}\text { 17a legislatura } \\
\text { (2011-2015) }\end{array}$ & 564 & 66 & $11,70 \%$ \\
\hline Total & 641 & 79 & $12,32 \%$ \\
\hline
\end{tabular}

Fonte: Site da ALMG. Elaboração própria.

Entretanto, essa quantidade de projetos representa apenas $12,32 \%$ da atuação desses deputados, quando se consideram todas as proposições apresentadas por esses 11 políticos selecionados. Isso refere-se a apenas 0,93\% a mais de projetos, vinculados a essa temática, em relação aos que foram apresentados pelo universo de deputados. Mostrando que a atuação desses deputados, para os grupos os quais eles representam descritivamente, pode ser considerada baixa.

Quando se analisa a situação final dessas proposições, apreende-se que a maioria delas é desarquivada ${ }^{13}(40,50 \%)$, enquanto, como foi visto acima em relação a atuação do total de deputados, a maioria das proposições foram transformadas em norma jurídica. Esses dados podem indicar que, quando se trata de deputados que apresentam alguma característica que os categoriza como pertencente a um grupo subalterno, o andamento e até mesmo a aprovação de um projeto e a sua transformação em norma jurídica pode ser um pouco mais difícil do que quando um deputado, que não possui essas mesmas caraterísticas, apresenta esse tipo de projeto. Isso é importante, pois pode auxiliar na explicação do motivo que leva esses parlamentares a não se engajarem muito nestas questões.

Mas, quando se observa as outras situações finais dos projetos, percebe-se que não é possível diferenciar a atuação de representantes descritivos do universo de

\footnotetext{
${ }^{13}$ Projetos desarquivados são aqueles que, como o nome já sugere, são desarquivados e podem seguir a tramitação a partir do estágio em que foram arquivados. Contudo, ao final da legislatura, se esses mesmos projetos ainda forem classificados como desarquivados, significa que nenhuma ação sobre eles foi tomada, podendo considerar que ficaram parados por esse período.
} 
Artigos | Relação entre representação descritiva e substantiva: o caso da Assembleia Legislativa de Minas Gerais (ALMG) (VIEIRA, Anne Karoline Rodrigues)

deputados, quando se é apresentado um projeto para minorias sociais. Os projetos rejeitados e retirados de tramitação não apresentam uma diferença significativa em relação aos dois casos, mas é um pouco maior para os representantes descritivos. 0 mesmo ocorre em relação às proposições arquivadas e vetadas totalmente, mas nesse caso elas são um pouco menores para os deputados foco da pesquisa.

\section{Gráfico 3}

Situação das proposições de representantes descritivos para minorias

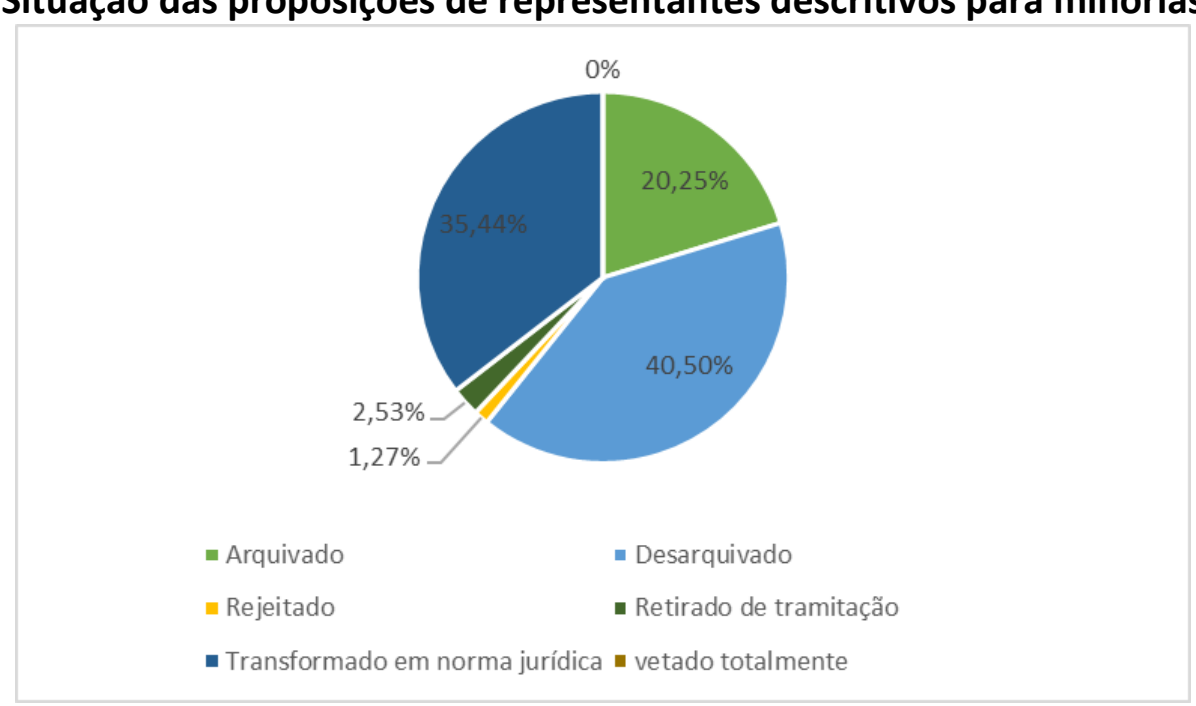

Fonte: ALMG. Elaboração própria.

Foi realizada, também, a análise em relação a quais grupos são direcionadas essas propostas. Os deputados que representam descritivamente as minorias sociais apresentam, em sua maioria, projetos para os aqui considerados como pessoas com deficiências e para os pobres. Trabalhadores manuais e/ou com funções subqualificadas e os negros apresentam a menor quantidade de projetos, enquanto os idosos e as mulheres podem ser considerados moderadamente representados. Algumas minorias não aparecem na atuação desses onze deputados, como o grupo LGBT, as comunidades tradicionais - que enquadram ribeirinhos e quilombolas - e os indígenas, o que demonstra um maior fechamento do campo político para esses grupos. 


\section{Gráfico 4}

\section{Grupos minoritários representados nas proposições dos representantes descritivos}

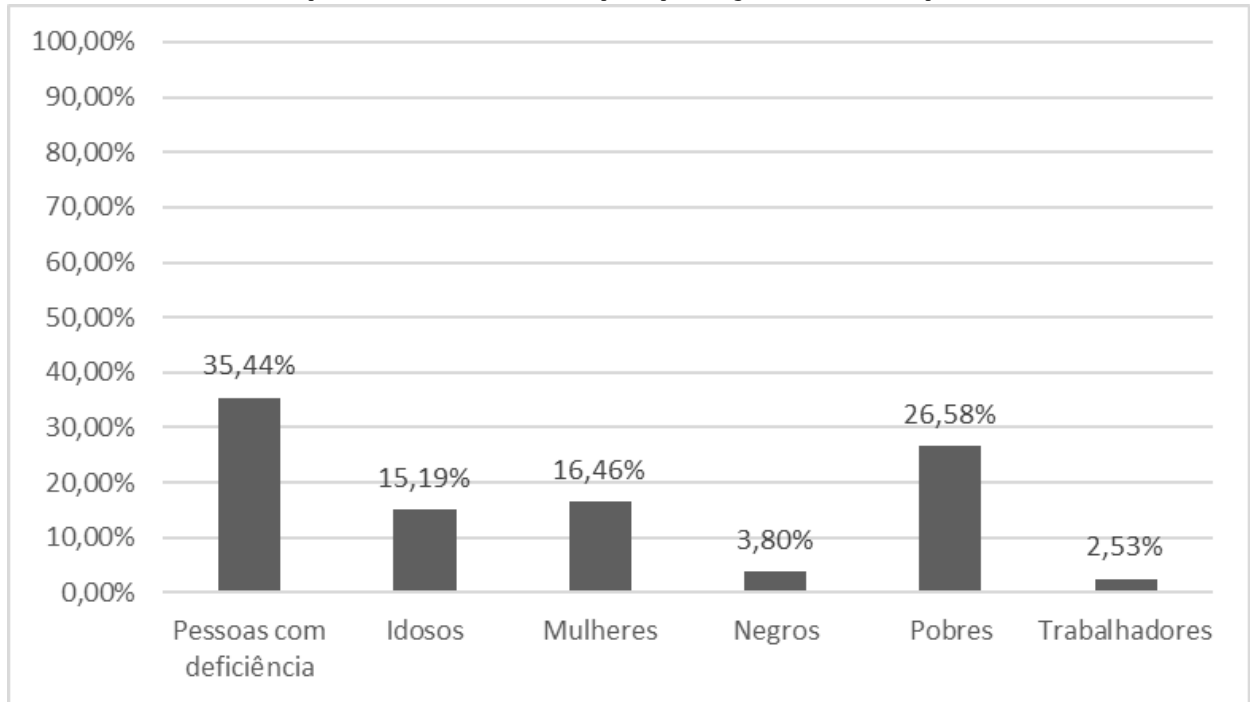

Fonte: ALMG. Elaboração própria.

Esses dados indicam que alguns grupos minoritários não contam com uma alta responsividade em relação as suas demandas, no legislativo mineiro, quando são analisadas a atuação de deputados que representam descritivamente esses mesmos grupos. Existe uma atuação para minorias sociais, mas para grupos que não são minoritários quantitativamente, a não ser no caso das pessoas com deficiências, mas para questões de relativo consenso social, como a questão da pobreza, e que são mais fáceis de serem discutidas e que, principalmente, encontram maior aceitação entre os eleitores.

\section{Considerações finais}

Quando se pensa em uma representação por perspectiva e identidade não se exige o controle político, mas social, com o fato de que há uma chance maior de que representantes descritivos compartilhem objetivos e tendências com os seus representados. Não é um mecanismo de certeza, mas sim de possibilidade de que isso ocorra. Considerando isso, o objetivo do trabalho foi perceber se, mesmo com uma pequena presença de representantes descritivos, existiria, nessas duas legislaturas estudadas, políticas que fossem responsivas aos grupos minoritários. Isso se deu a partir da análise dos projetos apresentados pelos deputados enquadrados aqui como 
Artigos | Relação entre representação descritiva e substantiva: o caso da Assembleia Legislativa de Minas Gerais (ALMG) (VIEIRA, Anne Karoline Rodrigues)

descritivos em relação a grupos como mulheres, negros e pessoas com baixa escolaridade.

Os resultados obtidos mostram que ser representante descritivo na ALMG durante as 11a e 17ạ legislaturas parece não estar vinculado a uma atuação intensa aos grupos minoritários, uma vez que os 11 deputados selecionados apresentaram apenas 0,93\% a mais de projetos, vinculados a essa temática, comparados com todos os deputados que passaram pela Casa no mesmo período. O que também pode indicar que não ser descritivamente igual a esses grupos não impede que se atue para as minorias, mas a presença e a atuação desses aliados não suprem a demanda por uma representação mais democrática e justa para segmentos excluídos da política. Mesmo que representantes de minorias não representem substantivamente, a sua presença nos espaços de poder seria justa e necessária para uma perspectiva mais igualitária de democracia.

Ainda, após a exposição dos achados, se percebeu que determinados grupos minoritários possuem políticas voltadas para os seus interesses, como os idosos, as pessoas carentes e os deficientes. Sendo importante, contudo, considerar o volume e a qualidade desses projetos. Essas minorias que foram alvo das proposições desses deputados, são minorias que contam com uma certa solidariedade e são menos radicais ou progressistas, como o grupo LGBT e os negros, que apresentam poucos ou nenhum projeto apresentado pelos deputados aqui selecionados. Assim, em algumas áreas, o número de projetos apresentados é pouco e versam, em sua maioria, sobre legislação de pouca relevância, que, como apontado acima, são projetos que visam o reconhecimento de instituições - declaração de utilidade pública -, ou doação de imóveis ou áreas públicas. Há de se considerar também, que possam existir projetos que poderiam atender esses grupos, mas não passaram pela seleção, por serem universais e englobarem diversos grupos, inclusive aqueles que não são enquadrados aqui como minorias.

Mesmo que se acredite que a representação descritiva ainda possa ser a melhor forma de dar voz para os grupos marginalizados, a sua vinculação com a representação substantiva pode não ser tão direta como se acredita, uma vez que muitos representantes descritivos podem não voltar a sua atuação para o grupo ao qual pertencem ou apresentar poucos projetos para esse grupo. Muitos fatores, como as 
Artigos | Relação entre representação descritiva e substantiva: o caso da Assembleia Legislativa de Minas Gerais (ALMG) (VIEIRA, Anne Karoline Rodrigues)

trajetórias individuais desses deputados, podem influenciar essa atuação e para descobri-los é necessária uma análise mais aprofundada. Outras variáveis podem explicar como o processo de construção do representado se dá, sendo que em alguns casos apenas incluir não é suficiente. Necessita-se observar outras características da organização do poder, da construção do representado e da falta de reflexividade, como é colocado por Pitkin (1967). Seria preciso aprimorar ainda mais o relacionamento que a própria autora destaca, mas não apenas isso. Para transformar, de fato, presença política em políticas substantivas direcionadas para estas minorias se requer muito mais.

\section{Referências}

ALMEIDA, Débora C. R. Representação além das eleições: Repensando as fronteiras entre Estado e sociedade. Jundiaí. Paco Editorial, 2015.

BEZERRA, M. Em nome das "bases". Política, favor e dependência pessoal. Rio de Janeiro: Relume-Dumará, 1999.

CARNES, Nicholas. Does the Numerical Underrepresentation of the Working Class in Congress Matter? Legislative studies quarterly, n. 37, v. 1, fev., 2012.

DOVI, Suzanne Lynn. Moving beyond descriptive representation. p. 27 - 51. In.: DOVI, Suzanne Lynn (2012 [1966]). The good representative. Wiley-Blackwell, 2012.

GRIFFIN, John; NEWMAN, Brian; WOLBRECHT, Christina. A Gender Gap in Policy Representation in the U.S. Congress? Legislative studies quarterly, n. 37, v. 1, fev., 2012.

MANSBRIDGE, J. Should Blacks Represent Blacks and Women Represent Women? A Contingent "Yes". The journal of politics, Vol. 61, No. 3, August, Pp. 628-57, 1999.

Rethinking representation. American Political Science Review. v. 97, n. 4, p. 515-527, nov., 2003.

MIGUEL, Luís Felipe. Democracia e representação: territórios em disputa. São Paulo: UNESP, 2014.

; FEITOSA, Fernanda. O Gênero do Discurso Parlamentar: Mulheres e Homens na Tribuna da Câmara dos Deputados. DADOS - Revista de Ciências Sociais, Rio de Janeiro, Vol. 52, no 1, pp. 201 a 221, 2009.

MILL, J. S. Considerações sobre o governo representativo. Brasília, UnB, 1981.

ORSATO, Andréia; GUGLIANO, Alfredo. A democracia desde a perspectiva de gênero: a representação política feminina na Assembleia Legislativa Gaúcha (1951-2012). 36o Encontro anual da ANPOCS (Associação de Pós-Graduação e Pesquisa em Ciências Sociais), em Águas de Lindóia - SP, Brasil, de 21 a 25 de outubro de 2012.

PHILLIPS, Anne. The politics of presence. Oxford University, 1998.

. De uma política de ideias a uma política de presença? Revista Estudos Feministas, Florianópolis, v. 9, n. 1, p. 268 -290, 2001.

. Da desigualdade à diferença: um caso grave de deslocamento? Revista

Brasileira de Ciência Política, no 2. Brasília, julho-dezembro, pp. 223-240, 2009. 
O que há de errado com a democracia liberal? Revista Brasileira de Ciência Política, no 6. Brasília, julho - dezembro, pp. 339-363, 2011.

PINHEIRO, Luana. Vozes femininas na política: uma análise sobre mulheres parlamentares no pós-Constituinte. Brasília: Secretaria Especial de Políticas para as Mulheres, 2007.

PITKIN, H. F. The concept of representation. Berkeley and Los Angeles: University of California, 1967.

. O Conceito de Representação. In: CARDOSO, Fernando Henrique; MARTINS, Carlos Estevam (org.). Política \& Sociedade. São Paulo: Companhia Editora Nacional, 1979. v. 2, 1979.

SEVERS, Eline. Representation as claims-making. Quid responsiveness? Representation, 46:4, 411-423, 2010.

WILLIAMS, M. S. Voice, Trust and Memory: marginalized groups and the failings of liberal representation. Princeton: Princeton University, 1998.

VIEIRA, Anne. Ambição política, perfis de carreira e representação de minorias: o caso da Assembleia Legislativa de Minas Gerais (ALMG). Revista Teoria \& Pesquisa, v. 28, n. 2, 2019, p. 71-100, 2019.

YOUNG, Iris Marion. Justice and the politics of difference. Princeton: Princeton University Press, 1990. Inclusion and democracy. Oxford: Oxford University, 2000. Representação Política, Identidade e Minorias. Lua Nova, 67, 2006. 